\title{
Sedative Medications for Critically III Children during and after Mechanical Ventilation: A Retrospective Observational Study
}

\author{
Deanna Caldwell, Jonathan Wong, and Mark Duffett
}

\begin{abstract}
Background: Providing safe and effective sedation to critically ill children is challenging. The assessment, prevention, and treatment of symptoms of iatrogenic withdrawal are critical aspects of sedation practice.

Objective: To describe the use of sedative medications in critically ill children at McMaster Children's Hospital.

Methods: This retrospective observational study included children admitted over a 12-month period who survived their illness and who received sedation and at least $48 \mathrm{~h}$ of invasive ventilation. We collected data from the time of admission to the pediatric intensive care unit to 3 days after discontinuation of sedation.

Results: We included 67 children. The median age was 1.6 (interquartile range $[\mathrm{IQR}] 0.2-6.2)$ years, and respiratory illnesses were the most common reason for admission (41 [61\%]). The children received invasive ventilation for a median of 7 (IQR 4-11) days and sedation for a median of 12 (IQR 6-20) days. Sixty-six children (99\%) received an opioid, and all received a benzodiazepine, with median cumulative doses of 14 (IQR $5-27) \mathrm{mg} / \mathrm{kg}$ morphine equivalents and 15 (IQR 6-32) mg/kg midazolam equivalents. Dexmedetomidine was given to 31 children $(46 \%)$, for a median of 8 (IQR 4-12) days. Most children (67\%) received sedation after extubation (median duration 7 [IQR 4-14] days). In addition, 32 children (48\%) continued to receive sedative medications after transfer to the ward, for a median of 6 (IQR 4-13) days. Forty-two children (63\%) had at least one Withdrawal Assessment Tool-1 (WAT-1) score indicative of iatrogenic withdrawal. Children who experienced withdrawal were exposed to more opioids and more benzodiazepines, both per day and overall, and for longer periods.
\end{abstract}

Conclusions: The children in this study were exposed to multiple sedatives, and many continued to receive these medications for an extended period after discontinuation of mechanical ventilation. Iatrogenic withdrawal was common and represents an important opportunity to improve children's recovery after critical illness.

Keywords: pediatrics, sedation, withdrawal

Can J Hosp Pharm. 2020;73(2):125-32

\section{RÉSUMÉ}

Contexte : Il est difficile d'offrir une sédation sûre et efficace aux enfants gravement malades. L'évaluation, la prévention et le traitement des symptômes du sevrage iatrogène sont des aspects critiques de la pratique de la sédation.

Objectif: Décrire l'usage de sédatifs pour les enfants gravement malades à l'Hôpital pour enfants McMaster.

Méthodes : Cette étude observationnelle rétrospective comprenait des enfants admis sur une période de 12 mois, ayant survécu à leur maladie et ayant reçu une sédation ainsi qu'une ventilation effractive d'au moins $48 \mathrm{~h}$. Nous avons recueilli des données à partir du moment de leur admission à l'unité de soins pédiatriques intensifs et jusqu’à trois jours après l'arrêt de la sédation.

Résultats : Nous avons inclus 67 enfants. L'âge moyen était 1,6 an (écart interquartile [IQR] 0,2-6,2), et les maladies respiratoires étaient la raison la plus fréquente (41 [61\%]). Les enfants ont reçu une ventilation effractive pendant 7 jours en moyenne (IQR 4-11) et une sédation pendant 12 jours en moyenne (IQR 6-20). Soixante-six (99 \%) enfants ont reçu un opiacé et ils ont tous reçu une benzodiazépine, avec des doses moyennes cumulées équivalentes à $14 \mathrm{mg} / \mathrm{kg}$ (IQR 5-27) de morphine et des doses moyennes cumulées équivalentes à 15 (IQR 6-32) mg/kg de midazolam. Trente et un (46\%) enfants ont reçu de la dexmédétomidine pendant huit jours en moyenne (IQR 4-12). La plupart (67\%) des enfants ont reçu une sédation après l'extubation (durée moyenne 7 [IQR 4-14] jours). De plus, 32 (48\%) enfants ont continué de recevoir des sédatifs après leur transfert dans leur chambre, et cela pendant six jours en moyenne (IQR 4-13). Les scores de quarante-deux (63\%) des enfants obtenus grâce à l'Outil d'évaluation du sevrage, version 1 [WAT-1], révèlent un sevrage iatrogène. Les enfants ayant ressenti des symptômes de sevrage ont été exposés à davantage d'opiacés et de benzodiazépines, aussi bien chaque jour que de manière globale, mais également pendant des périodes prolongées.

Conclusions : Les enfants de cette étude ont été exposés à plusieurs sédatifs et bon nombre d'entre eux ont continué à recevoir ces médicaments pendant une période prolongée après l'arrêt de la ventilation mécanique. Le sevrage iatrogène se pratiquait couramment; il s'agit d'une belle occasion d'améliorer la convalescence des enfants après une maladie grave.

Mots-clés : pédiatrie, sédation, sevrage 


\section{INTRODUCTION}

$\mathrm{B}$ alancing the benefits and harms of sedatives in critically ill children is challenging. Sedatives are commonly used to reduce agitation and facilitate mechanical ventilation, but prolonged exposure to these medications is associated with poorer outcomes, including prolonged duration of mechanical ventilation, pediatric intensive care (PICU) stay, and iatrogenic withdrawal. ${ }^{1-3}$ Despite the almost universal use of sedatives, the best approach for sedation liberation - the weaning and discontinuation of sedative medications, and the assessment, prevention, and treatment of iatrogenic withdrawal-remains unclear.

Withdrawal after prolonged exposure to sedatives is common in children, with estimates ranging from $45 \%$ to $86 \%$. $^{4}$ This variation may be due to differences in patient populations, sedative exposure, and assessment methods among studies. The assessment of withdrawal is based on a combination of central nervous system symptoms (e.g., anxiety or agitation), gastrointestinal symptoms (e.g., vomiting or diarrhea), and autonomic symptoms (e.g., sweating or tachycardia) according to validated scores, such as the Withdrawal Assessment Tool version 1 (WAT-1) 5 or the Sophia Observation Withdrawal Symptoms Scale. ${ }^{6}$ Two general approaches have been studied to reduce rates of withdrawal. The first of these are strategies to reduce sedative exposure, given that withdrawal has been associated with increased dose and duration of opioid and benzodiazepine exposure. ${ }^{3,7}$ Both protocol-based sedation and the addition of an $\alpha$-agonist have been studied, but without any difference in rates of withdrawal..$^{8-12}$ The second general approach involves various methods of weaning sedatives after extubation. It has been hypothesized that a slower rate of weaning may prevent withdrawal, but this has not been proven in studies to date. Two randomized controlled trials enrolling a total of 115 children compared methadone weaning schedules and found that different doses or durations of tapering were not associated with reduced incidence of withdrawal. ${ }^{13,14}$ Unfortunately, children experiencing withdrawal generally require additional monitoring, additional sedative medications (including prolonged tapering), and longer stays in the PICU and in hospital than children not experiencing withdrawal. ${ }^{2,3}$ In addition, the effects of withdrawal on the children themselves, on their families, and on clinicians have not been well studied.

The objective of this study was to describe the use of sedative medications in critically ill children at McMaster Children's Hospital, in Hamilton, Ontario, specifically the exposure to sedation (during and after mechanical ventilation), the incidence and duration of iatrogenic withdrawal, and the association between patient characteristics and medication exposure and withdrawal. Our ultimate goals were to inform local efforts to improve the management of sedation and to allow centres to compare their practices. This study also provides a foundation for future research on interventions to improve sedation-related outcomes and research to identify the most appropriate and efficient metrics to measure the process of liberating children from sedatives.

\section{METHODS}

\section{Study Design}

This retrospective observational study was conducted in a 12-bed, medical-surgical PICU at a tertiary academic centre that does not perform cardiac surgery. Sedation, including weaning of sedatives and management of withdrawal, is at the discretion of individual physicians, without set protocols. WAT-1 scoring is performed at the discretion of the clinical team when patients are thought to be at high risk of withdrawal or withdrawal is clinically suspected. We included all children who required invasive ventilation for a minimum of $48 \mathrm{~h}$ and who received at least 1 dose of any sedative between July 1, 2016, and June 30, 2017. We hypothesized that children receiving sedation for less than $48 \mathrm{~h}$ would be very unlikely to have sedation weaned or to experience withdrawal. We excluded children who were admitted for status epilepticus and those who did not survive to discharge from hospital. For children with multiple eligible PICU admissions, we selected 1 admission at random. This study was approved by the Hamilton Integrated Research Ethics Board, which waived the need for consent.

\section{Data Collection and Outcomes}

We extracted data from each child's medical records, including age, sex, weight, home use of opioids or benzodiazepines, and admission diagnosis, and we used the Pediatric Index of Mortality ${ }^{15}$ and Pediatric Logistic Organ Dysfunction ${ }^{16}$ scores to assess severity of illness. We also collected the WAT-1 scores documented by bedside nurses and the doses, routes, and modes of administration of all sedative and analgesic medications, from PICU admission to $72 \mathrm{~h}$ after discontinuation of sedation, or to hospital transfer or discharge, whichever occurred first. ${ }^{5}$

\section{Data Analysis and Reporting}

We converted all opioids to parenteral morphine equivalents (fentanyl $0.015 \mathrm{mg} / \mathrm{kg}$ and hydromorphone $0.15 \mathrm{mg} / \mathrm{kg}=$ morphine $1 \mathrm{mg} / \mathrm{kg}$ ) and benzodiazepines to midazolam equivalents (lorazepam $0.3 \mathrm{mg} / \mathrm{kg}=$ midazolam $1 \mathrm{mg} / \mathrm{kg}$ ). ${ }^{8}$ For enterally administered drugs, we assumed bioavailability of $33 \%$ for opioids and $100 \%$ for lorazepam. To describe patterns of medication usage, we considered 3 phases of sedation: early mechanical ventilation (less than or equal to the first quartile of the overall duration of mechanical ventilation in this study), late mechanical ventilation (greater than the first quartile), and after extubation. We considered a WAT-1 score of 3 or more as indicating iatrogenic withdrawal on that day and assumed that a patient was not experiencing withdrawal if no WAT-1 scores were documented. We reported the data as medians (with interquartile ranges [IQRs]) or counts (with percentages). We used the MannWhitney $U$ test and the Fisher exact test to compare those with 
and without withdrawal. We used $\mathrm{R}$ software, version 3.5.3 (R Foundation for Statistical Computing, Vienna, Austria), to perform the analyses and $p<0.05$ as the criterion for statistical significance.

\section{RESULTS}

\section{Included Children}

We included 67 children between 3 days and 16 years of age (median 1.6 [IQR 0.2-6.2] years). Figure 1 shows the study flow diagram, and Table 1 shows the characteristics of the included children. The most common type of reason for admission was respiratory illness (41 [61\%]). The children received invasive mechanical ventilation for a median of 7 (IQR 4-11) days and were admitted to the PICU for a median of 10 (IQR 6-14) days.

\section{Exposure to Sedatives}

Overall, children in this study received 11 different sedatives and received sedation for a median of 12 (IQR 6-20) days. Table 2 lists the sedatives received along with their respective durations of exposure. All children received a benzodiazepine, and 66 (99\%) received an opioid, for a median duration of 9 (IQR 4-15) and 10 (IQR 5-19) days, respectively (Table 2). The median day on which children reached their peak opioid and benzodiazepine dose was day 3 (IQR 2-6) and day 4 (IQR 2-6), respectively. Sixtytwo children (93\%) received sedative agents other than opioids and benzodiazepines, with dexmedetomidine and propofol being the most common. Similar to opioids and benzodiazepines, dexmedetomidine was used for a median of 8 (IQR 4-12) days, but the peak dose occurred later, at a median of day 7 (IQR 6-10) days. The children were exposed to a median cumulative dose of 14 (IQR 5-27) $\mathrm{mg} / \mathrm{kg}$ morphine equivalents and 15 (IQR 6-32) $\mathrm{mg} / \mathrm{kg}$ midazolam equivalents. Doses given on an as-needed basis contributed to $25 \%$ and $30 \%$ of the total doses of opioids and benzodiazepines, respectively.

Almost all children (66 [99\%]) received multiple sedatives (maximum 7) from multiple drug classes. Figure 2 shows the

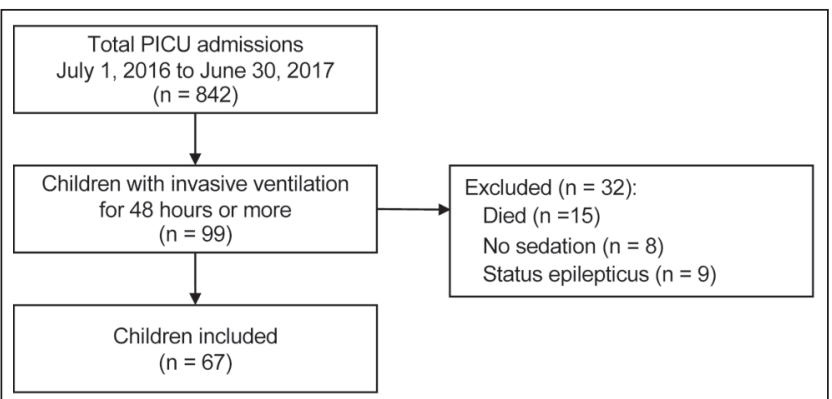

Figure 1. Study flow diagram.

PICU = pediatric intensive care unit. patterns of drug choice and combinations for the early (days 1 to 4) and late (day 5 to extubation) phases of mechanical ventilation and after extubation. After extubation, 45 children (67\%) received sedative medications for a median of 7 (IQR 4-14) days. Twentyfive children $(37 \%)$ continued to receive sedatives by continuous infusion for a median of 3 (IQR 1-3) days, and 36 (54\%) received oral medications for a median of 9 (IQR 4-14) days. Additionally, 32 children (48\%) received sedative medication after transfer to the ward, for a median of 6 (IQR 4-13) days.

Table 1. Characteristics of Included Children

\begin{tabular}{|c|c|c|}
\hline Characteristic & & $\begin{array}{l}\text { \%) of } \\
\text { dren* } \\
\text { : 67) }\end{array}$ \\
\hline$\overline{\text { Age }}$ & & \\
\hline$<1$ month & 6 & $(9 \%)$ \\
\hline $1-12$ months & 25 & $(37 \%)$ \\
\hline $1-5$ years & 19 & $(28 \%)$ \\
\hline $6-12$ years & 10 & $(15 \%)$ \\
\hline$>12$ years & 7 & $(10 \%)$ \\
\hline Sex, male & 43 & $(64 \%)$ \\
\hline Weight (kg) (median and IQR) & 10 & $(5-21)$ \\
\hline $\begin{array}{l}\text { Opioid or benzodiazepine use before } \\
\text { PICU admission }\end{array}$ & 4 & $(6 \%)$ \\
\hline Predicted risk of death $\dagger$ & & \\
\hline Median (IQR) & $1.1 \%$ & $3 \%-3.7 \%)$ \\
\hline Maximum & & $3 \%$ \\
\hline PELOD score (maximum per patient) & & \\
\hline Median (IQR) & 12 & $(2-21)$ \\
\hline Maximum & & 2 \\
\hline Reason for PICU admission & & \\
\hline Medical & 56 & $(84 \%)$ \\
\hline Bronchiolitis & 24 & $(36 \%)$ \\
\hline Pneumonia & 9 & $(13 \%)$ \\
\hline Sepsis or septic shock & 5 & $(7 \%)$ \\
\hline Neurologic & 6 & $(9 \%)$ \\
\hline Other medical & 12 & $(18 \%)$ \\
\hline Surgical & 9 & $(13 \%)$ \\
\hline Trauma & 2 & $(3 \%)$ \\
\hline Duration of admission (days) & & \\
\hline PICU & & \\
\hline Median (IQR) & 10 & $(6-14)$ \\
\hline Maximum & & 8 \\
\hline Hospital & & \\
\hline Median (IQR) & 17 & $(11-29)$ \\
\hline Maximum & & 52 \\
\hline Duration of invasive ventilation (days) & & \\
\hline Median (IQR) & 7 & $(4-11)$ \\
\hline Maximum & & 5 \\
\hline Disposition on PICU discharge & & \\
\hline Ward & 59 & $(88 \%)$ \\
\hline Home & 6 & $(9 \%)$ \\
\hline Another PICU & 2 & $(3 \%)$ \\
\hline $\begin{array}{l}\mathrm{IQR}=\text { interquartile range, } \mathrm{PELOD}=\mathrm{Pec} \\
\text { Dysfunction, PICU = pediatric intensive } \\
\text { *Except where indicated otherwise. } \\
\text { †Based on the Pediatric Index of Mort }\end{array}$ & stic Or & \\
\hline
\end{tabular}


Table 2. Sedatives Used

\begin{tabular}{|c|c|c|c|c|c|c|}
\hline \multirow[t]{2}{*}{ Medication } & \multirow{2}{*}{$\begin{array}{l}\text { Duration of } \\
\text { Therapy (Days) } \\
\text { Median (IQR) }\end{array}$} & \multicolumn{5}{|c|}{ Timing; No. (\%) of Children Receiving Medication $(n=67)$} \\
\hline & & \multicolumn{2}{|c|}{ Any Time } & $\begin{array}{c}\text { Early } \\
\text { (Days 1-4) }\end{array}$ & $\begin{array}{c}\text { Late (Day } 5 \\
\text { to Extubation)* }\end{array}$ & $\begin{array}{c}\text { After } \\
\text { Extubation }\end{array}$ \\
\hline Any opioid & $10(5-19)$ & 66 & $(99 \%)$ & $62(93 \%)$ & $50(98 \%)$ & $40(60 \%)$ \\
\hline Continuous infusion & $7(3-10)$ & 60 & $(90 \%)$ & $54(81 \%)$ & $41(80 \%)$ & $20(30 \%)$ \\
\hline Fentanyl & $6(2-9)$ & 60 & $(90 \%)$ & $55(82 \%)$ & $39(76 \%)$ & $14(21 \%)$ \\
\hline Continuous infusion & $6(3-9)$ & 51 & $(76 \%)$ & $45(67 \%)$ & $35(69 \%)$ & $11(16 \%)$ \\
\hline Hydromorphone & $10(5-16)$ & 32 & $(48 \%)$ & $12(18 \%)$ & $22(43 \%)$ & $26(39 \%)$ \\
\hline Continuous infusion & $7(3-11)$ & 10 & $(15 \%)$ & $6 \quad(9 \%)$ & $5(10 \%)$ & $8(12 \%)$ \\
\hline Morphine & $2(1-6)$ & 43 & $(64 \%)$ & $27(40 \%)$ & $18(35 \%)$ & $17(25 \%)$ \\
\hline Continuous infusion & $3(2-3)$ & 15 & $(22 \%)$ & $10(15 \%)$ & $8(16 \%)$ & $2(3 \%)$ \\
\hline Remifentanil & $1(1-1)$ & 0 & & 0 & $1 \quad(2 \%)$ & 0 \\
\hline \multicolumn{7}{|l|}{ Benzodiazepines } \\
\hline Any benzodiazepine & $9(4-15)$ & 67 & $(100 \%)$ & $63(94 \%)$ & 49 (96\%) & $35 \quad(52 \%)$ \\
\hline Lorazepam & $4(2-10)$ & 50 & $(75 \%)$ & $23(34 \%)$ & $31 \quad(61 \%)$ & $32(48 \%)$ \\
\hline Midazolam & $6(4-9)$ & 65 & $(97 \%)$ & $61 \quad(91 \%)$ & $46(90 \%)$ & $16(24 \%)$ \\
\hline Continuous infusion & $6(3-9)$ & 62 & $(93 \%)$ & $57 \quad(85 \%)$ & $43(84 \%)$ & $15(22 \%)$ \\
\hline \multicolumn{7}{|l|}{ Alpha agonists } \\
\hline Any $\alpha$-agonist & $16(7-28)$ & 35 & $(52 \%)$ & $19(28 \%)$ & $31 \quad(61 \%)$ & $28(42 \%)$ \\
\hline Clonidine & $9(7-16)$ & 26 & $(39 \%)$ & $1 \quad(1 \%)$ & $7(14 \%)$ & $26(39 \%)$ \\
\hline Dexmedetomidine & $8(4-12)$ & 31 & $(46 \%)$ & $18(27 \%)$ & $27(53 \%)$ & $21(31 \%)$ \\
\hline \multicolumn{7}{|l|}{ Other sedatives } \\
\hline Any other sedative & $6(2-10)$ & 62 & $(93 \%)$ & $53(79 \%)$ & $43(84 \%)$ & $13(19 \%)$ \\
\hline Chloral hydrate & $3(2-6)$ & 28 & $(42 \%)$ & $17(25 \%)$ & $21(41 \%)$ & $7(10 \%)$ \\
\hline Ketamine & $1(1-1)$ & 23 & $(34 \%)$ & $14(21 \%)$ & $10(20 \%)$ & $2 \quad(3 \%)$ \\
\hline Continuous infusion & $3(2-4)$ & 3 & $(4 \%)$ & $2 \quad(3 \%)$ & $1 \quad(2 \%)$ & 0 \\
\hline Propofol & $3(2-6)$ & 60 & $(90 \%)$ & $47 \quad(70 \%)$ & 43 (84\%) & $8(12 \%)$ \\
\hline Continuous infusion & $2(1-2)$ & 39 & $(58 \%)$ & $16(24 \%)$ & $28 \quad(55 \%)$ & $3(4 \%)$ \\
\hline
\end{tabular}

*The denominator for this column is the 51 children who were ventilated for 5 days or more.

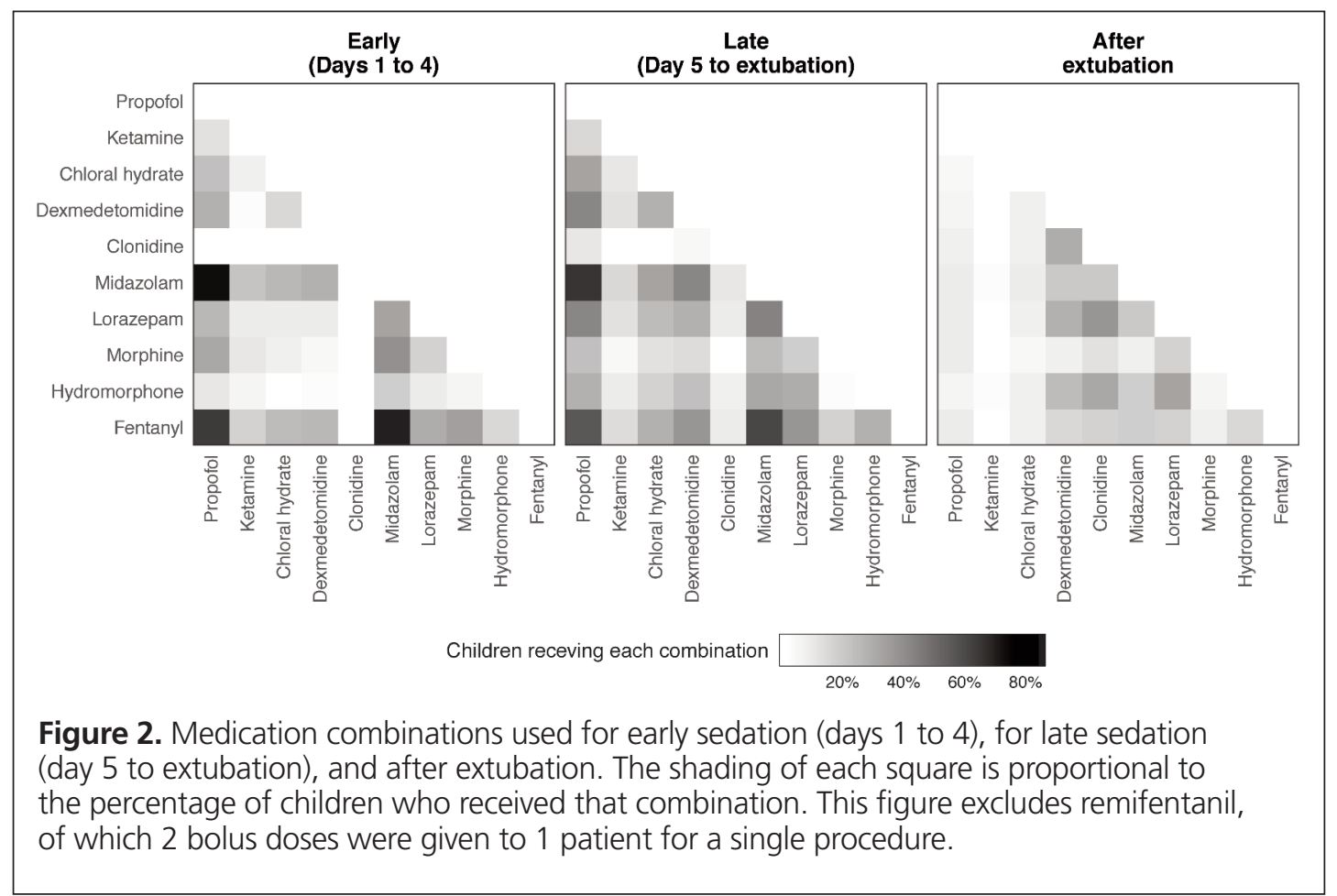



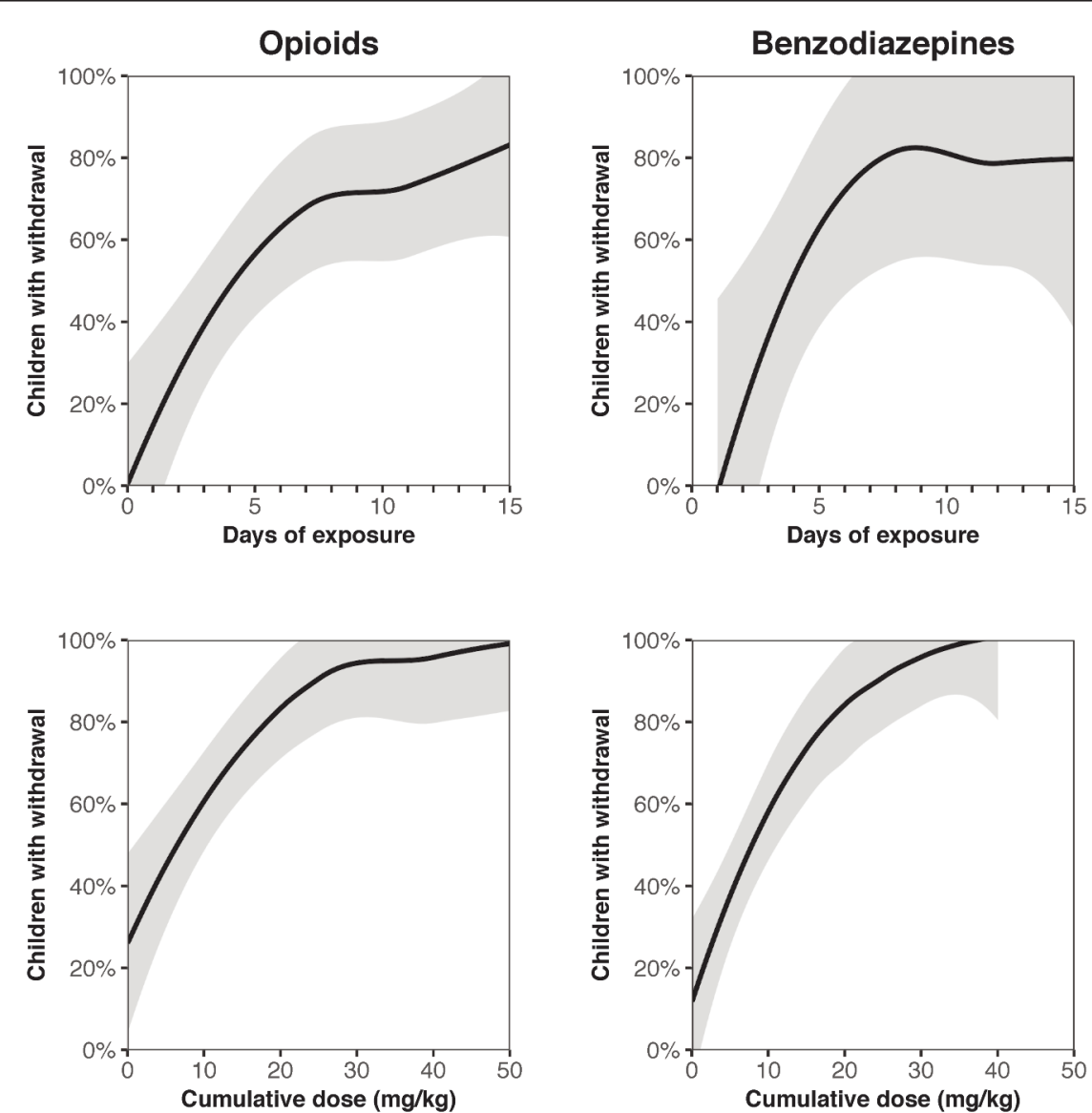

Figure 3. Occurrence of withdrawal in relation to duration and cumulative dose of opioids and benzodiazepines. The black line shows the percentage of children who experienced withdrawal according to the duration of exposure or cumulative dose before the first recorded instance of withdrawal. The shaded area shows the 95\% confidence interval.

\section{latrogenic Withdrawal}

WAT-1 scores were documented for 47 children (70\%). These children were assessed a median of 41 (IQR 21-82) times in total on a median of 9 (IQR 5-16) days each. The median number of scores documented per day was 5 (IQR 4-5). Fortytwo $(63 \%)$ of the 67 children had at least one WAT-1 score of 3 or more, indicating iatrogenic withdrawal. Withdrawal first occurred at a median of 5 (IQR 7-11) days after PICU admission. The median duration of withdrawal was 4 (IQR 2-8) days, and 18 children ( $43 \%$ of those in withdrawal and $27 \%$ of all children in the study) experienced withdrawal on the ward after discharge from the PICU. Figure 3 shows the association between the occurrence of withdrawal and the duration and cumulative dose of opioids and benzodiazepines. There were no differences in age or severity of illness, but compared with children who did not experience withdrawal, those who did experience withdrawal were exposed to higher total doses of opioids, benzodiazepines, and dexmedetomidine before their first recorded instance of withdrawal (Table 3, Figure 4). In addition, they required more days of ventilation and stayed longer in the PICU and in hospital.

\section{DISCUSSION}

In this retrospective observational study, we found that children were exposed to many different sedatives and that the patterns of use changed over the course of their illness and recovery. Many continued to receive sedatives for an extended period after discontinuation of mechanical ventilation and after transfer to the ward. Iatrogenic withdrawal was common, and the frequency of withdrawal was greater with higher doses and longer duration of sedation.

Our overall findings with respect to sedation exposure and withdrawal are consistent with those from other centres in North America. In a randomized controlled trial (RCT), Curley and others $^{8}$ compared protocol-based sedation with usual care in 2449 children in 31 PICUs in the United States. The patients at our centre, when compared with the usual care group in the RCT, ${ }^{8}$ had similar duration of ventilation (median 7 versus 
This single copy is for your personal, non-commercial use only.

For permission to reprint multiple copies or to order presentation-ready copies for distribution, contact CJHP at publications@cshp.ca

\section{Table 3. Characteristics of Children Who Did and Did Not Experience Withdrawal}

\begin{tabular}{|c|c|c|c|}
\hline \multirow[b]{2}{*}{ Characteristic } & \multicolumn{2}{|c|}{ Group; Median (IQR)* } & \multirow[b]{2}{*}{$p$ Valuet } \\
\hline & $\begin{array}{l}\text { Withdrawal } \\
\quad(n=42)\end{array}$ & $\begin{array}{l}\text { No Withdrawal } \\
(n=25)\end{array}$ & \\
\hline Age (years) & $1.3(0.4-4.5)$ & $2.3(0.1-7.6)$ & 0.71 \\
\hline Sex, male, no. (\%) of children & $32(76 \%)$ & $11(44 \%)$ & 0.002 \\
\hline No. (\%) with opioid or benzodiazepine use before PICU admission & $3(7 \%)$ & $1(4 \%)$ & $>0.99$ \\
\hline Predicted risk of death $\neq$ & $1.0 \%(0.6 \%-2.9 \%)$ & $2.8 \%(0.9 \%-4.2 \%)$ & 0.11 \\
\hline \multicolumn{4}{|l|}{ Opioids§ } \\
\hline Total dose (mg/kg morphine equivalents) & $8(13-25)$ & $(1-7)$ & $<0.001$ \\
\hline Dose per day (mg/kg morphine equivalents) & $2.5(1.5-3.2)$ & $0.6(0.3-1.2)$ & $<0.001$ \\
\hline Days of therapy & $7 \quad(6-8)$ & $(3-8)$ & $<0.001$ \\
\hline \multicolumn{4}{|l|}{ Benzodiazepines§ } \\
\hline Total dose (mg/kg midazolam equivalents) & $20(14-31)$ & $(2-8)$ & $<0.001$ \\
\hline Dose per day (mg/kg midazolam equivalents) & $2.7(1.8-3.6)$ & $1.2(0.4-1.9)$ & $<0.001$ \\
\hline Days of therapy & $(6-8)$ & $(2-6)$ & $<0.001$ \\
\hline \multicolumn{4}{|l|}{ Dexmedetomidine§ } \\
\hline Total dose (mg/kg) & $62(0-136)$ & $(0-0)$ & $<0.001$ \\
\hline Dose per day $(\mathrm{mg} / \mathrm{kg}) \uparrow$ & $18 \quad(9-20)$ & $15(10-16)$ & 0.32 \\
\hline Days of therapy & $(0-6)$ & $(0-0)$ & $<0.001$ \\
\hline \multicolumn{4}{|l|}{ Clinical outcomes } \\
\hline Invasive ventilation (days) & $8 \quad(6-11)$ & $(3-5)$ & $<0.001$ \\
\hline PICU stay (days) & $11 \quad(8-15)$ & $(3-10)$ & $<0.001$ \\
\hline Hospital stay (days) & $19(14-33)$ & $(6-17)$ & 0.002 \\
\hline
\end{tabular}

$\mathrm{IQR}=$ interquartile range, $\mathrm{PICU}=$ pediatric intensive care unit.

*Except where indicated otherwise.

†Mann-Whitney $U$ test or the Fisher exact test.

fUsing the Pediatric Index of Mortality score. ${ }^{15}$

$\S$ For the withdrawal group, these data include only drugs given before the first day of withdrawal.

IDose administered on days that the patient was exposed to the drug.

7 days), similar duration of opioid therapy (median 10 versus 10 days), similar total doses of opioids ( 14 versus $18 \mathrm{mg} / \mathrm{kg}$ ) and benzodiazepines ( 15 versus $14 \mathrm{mg} / \mathrm{kg}$ ), and similar incidence of withdrawal (63\% versus $68 \%)$, respectively. There were also some differences, particularly with respect to the medications used after extubation. None of the children at our centre received methadone, and $39 \%$ received clonidine, whereas in the usual care group of Curley and others ${ }^{8}$ these rates were $30 \%$ and $13 \%$, respectively. In our study, increased dose and duration of opioids, benzodiazepines, and dexmedetomidine were all associated with withdrawal. Although opioids and benzodiazepines are wellestablished risk factors for withdrawal, we hypothesize that the effect of dexmedetomidine represents confounding by indication, whereby this drug was selectively used for children at high risk of withdrawal.

The results of this study highlight the importance of sedation liberation and the need for quality improvement and further research. We observed a high incidence of iatrogenic withdrawal, which affected the majority of children ventilated for longer than $48 \mathrm{~h}$. In addition, we observed prolonged administration of sedatives after extubation, for a median of 7 days, which was similar to the median duration of ventilation. We hypothesize that withdrawal and the sedation liberation process may have important effects on quality of life for both children and their parents, as well as on clinician workload. We were unable to measure such effects in our study, but if present, they could be due to withdrawal symptoms, adverse effects of medications, and delay of children's return to normal functioning after their critical illness (through prolongation of the need for IV access, increased acuity of care, and need for additional monitoring). The results of this study also highlight the importance of a system-wide approach to managing care for these children and improving their recovery from critical illness. After transfer to the ward, almost one-third of the children (29\%) continued to experience withdrawal, and nearly half (48\%) continued to receive sedative medications. Clearly, weaning and discontinuation of sedation and iatrogenic withdrawal are challenges for clinicians on pediatric and surgical wards, not just within the PICU.

To facilitate quality improvement and research studies of interventions to improve this process, future studies should focus on defining the most appropriate and efficient metrics to measure the process of liberating children from sedatives. Such studies should investigate methods to describe children's sedative exposure, given that almost all critically ill children receive multiple medications and given that the dose, duration, timing, and choice of drugs, as well as the duration and complexity of the weaning process, are all potentially relevant factors. Additionally, the effects of score-based diagnosis, including use of the WAT-1 


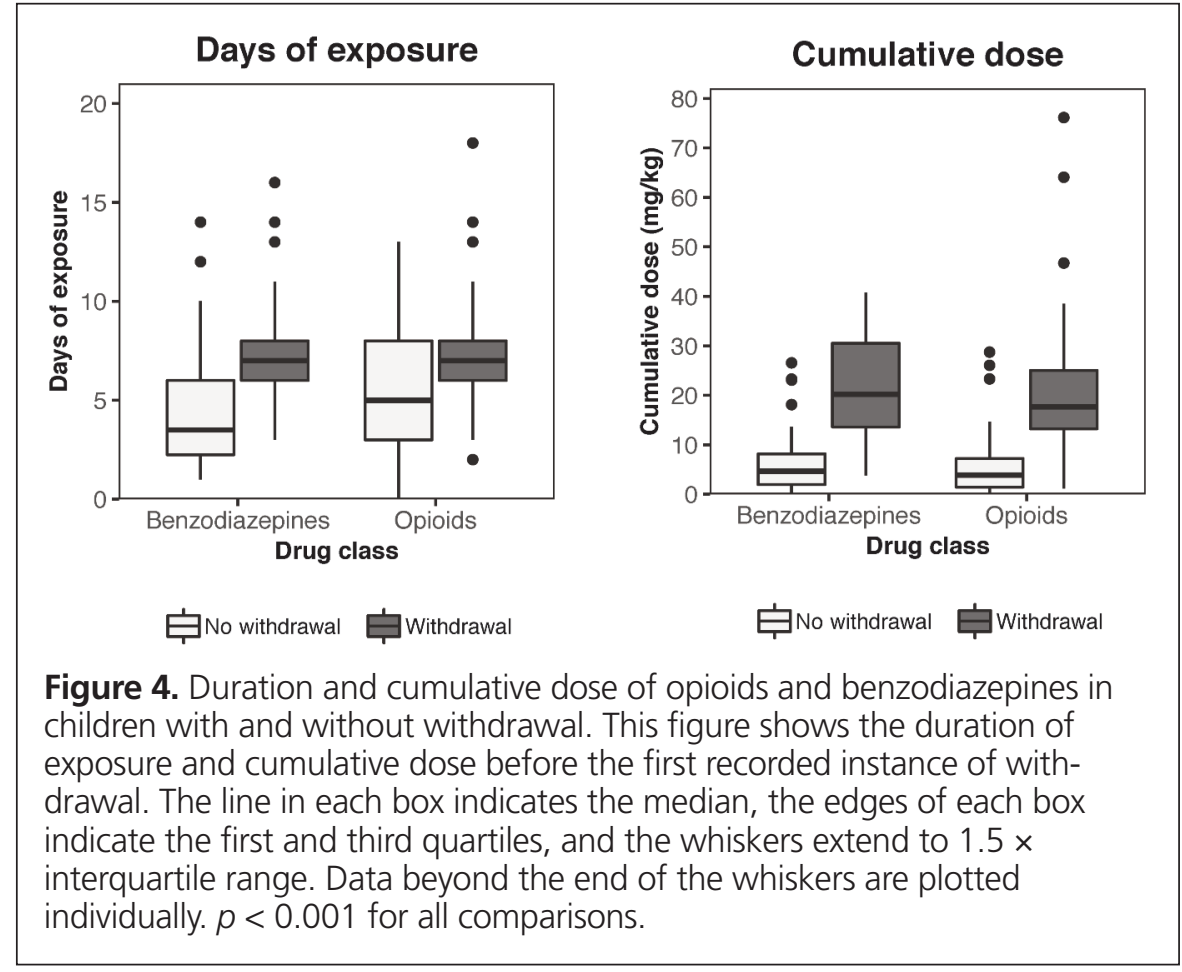

score, on clinical, patient, and parental outcomes should be assessed. We defined withdrawal as a single score of 3 or more; other criteria may be more specific. Throughout the course of each child's illness and recovery, medication doses were frequently titrated and sedation targets and medication choices were changed; as a result, we were unable to determine, as we had intended, when the sedation weaning process for each child began. Finally, insight into the priorities and preferences of patients, families, and clinicians with regard to sedation, weaning, and withdrawal are critical to selecting outcomes for future studies of interventions to improve the sedation liberation process.

The strengths of this study included its broad inclusion criteria and granular, daily data collection. In addition, we collected data from before and after extubation and from both the PICU and the ward, to capture the full trajectory of each child's illness and recovery. We included all eligible children admitted to the PICU during a complete calendar year to minimize the effect of seasonal variation and differences among prescribers. This study also had some limitations. We were unable to measure some aspects of the process of discontinuing sedation, such as the clinical rationale for drug choices and dosing, nor could we measure clinician workload. We could not distinguish medications given for sedation or withdrawal from those that were administered for analgesia or procedures. Not all children were assessed for withdrawal with the WAT-1 score. Because this scoring was completed according to clinical suspicion, it is possible that the true incidence of withdrawal was higher. In addition, delirium scores were not routinely used at the time of this study.
We were also unable to fully assess the risk factors for withdrawal because of the small number of children, both overall and among those who did not experience withdrawal. Finally, although our results were consistent with those of other studies, the extent to which our local practice is generalizable to other centres is uncertain because of differences in patient population, sedation protocols, and sedative agents of choice.

\section{CONCLUSION}

In this retrospective observational study, we found that children were exposed to many different sedatives and that patterns of use changed over the course of their illness and recovery. Many of the children continued to receive sedatives for an extended period after mechanical ventilation was discontinued. Iatrogenic withdrawal remained common and represents an important opportunity to improve children's recovery after critical illness.

\section{References}

1. Vet NJ, Ista E, De Wildt SN, Van Dijk M, Tibboel D, De Hoog M. Optimal sedation in pediatric intensive care patients: a systematic review. Intensive Care Med. 2013;39(9):1524-34.

2. Chiu AW, Contreras S, Mehta S, Korman J, Perreault MM, Williamson DR, et al. Iatrogenic opioid withdrawal in critically ill patients: a review of assessment tools and management. Ann Pharmacother. 2017;51(12):1099-111.

3. Anand KJS, Willson DF, Berger J, Harrison R, Meert KL, Zimmerman J, et al. Tolerance and withdrawal from prolonged opioid use in critically ill children. Pediatrics. 2010;125(5):e1208-25.

4. Fenn NE 3rd, Plake KS. Opioid and benzodiazepine weaning in pediatric patients: review of current literature. Pharmacotherapy. 2017;37(11): 1458-68.

5. Franck LS, Scoppettuolo LA, Wypij D, Curley MAQ. Validity and generalizability of the Withdrawal Assessment Tool-1 (WAT-1) for monitor- 
This single copy is for your personal, non-commercial use only.

For permission to reprint multiple copies or to order presentation-ready copies for distribution, contact CHHP at publications@cshp.ca

ing iatrogenic withdrawal syndrome in pediatric patients. Pain. 2012; 153(1):142-8

6. Ista E, Van Dijk M, De Hoog M, Tibboel D, Duivenvoorden HJ. Construction of the Sophia Observation withdrawal Symptoms-scale (SOS) for critically ill children. Intensive Care Med. 2009;35(6):1075-81.

7. Best K, Boullata J, Curley M. Risk factors associated with iatrogenic opioid and benzodiazepine withdrawal in critically ill pediatric patients: a systematic review and conceptual model. Pediatr Crit Care Med. 2015;16(2):175-83.

8. Curley MAQ, Wypij D, Watson RS, Grant MJC, Asaro LA, Cheifetz IM, et al. Protocolized sedation vs usual care in pediatric patients mechanically ventilated for acute respiratory failure: a randomized clinical trial. JAMA. 2015;313(4):379-89.

9. Hünseler C, Balling G, Röhlig C, Blickheuser R, Trieschmann U, Lieser U, et al. Continuous infusion of clonidine in ventilated newborns and infants. Pediatr Crit Care Med. 2014;15(6):511-22.

10. Vet NJ, de Wildt SN, Verlaat CWM, Knibbe CAJ, Mooij MG, van Woensel JBM, et al. A randomized controlled trial of daily sedation interruption in critically ill children. Intensive Care Med. 2016;42(2):233-44.

11. Wolf A, McKay A, Spowart C, Granville H, Boland A, Petrou S, et al. Prospective multicentre randomised, double-blind, equivalence study comparing clonidine and midazolam as intravenous sedative agents in critically ill children: the SLEEPS (safety profile, efficacy and equivalence in paediatric intensive care sedation) study. Health Technol Assess. 2014;18(71): $1-212$.

12. Schneider JB, Sweberg T, Asaro LA, Kirby A, Wypij D, Thiagarajan RR, et al. Sedation management in children supported on extracorporeal membrane oxygenation for acute respiratory failure. Crit Care Med. 2017;45(10): e1001-10.

13. Berens RJ, Meyer MT, Mikhailov TA, Colpaert KD, Czarnecki ML, Ghanayem NS, et al. A prospective evaluation of opioid weaning in opioid-dependent pediatric critical care patients. Anesth Analg. 2006; 102(4):1045-50.

14. Bowens CD, Thompson JA, Thompson MT, Breitzka RL, Thompson DG, Sheeran PW. A trial of methadone tapering schedules in pediatric intensive care unit patients exposed to prolonged sedative infusions. Pediatr Crit Care Med. 2011;12(5):504-11.
15. Slater A, Shann F, Pearson G; Paediatric Index of Mortality (PIM) Study Group. PIM2: a revised version of the Paediatric Index of Mortality. Intensive Care Med. 2003;29(2):278-85.

16. Leteurtre S, Martinot A, Duhamel A, Proulx F, Grandbastien B, Cotting J, et al. Validation of the paediatric logistic organ dysfunction (PELOD) score: prospective, observational, multicentre study. Lancet. 2003;362 (9379):192-7.

Deanna Caldwell, PharmD, ACPR, RPh, was, at the time of this study, a pharmacy resident at McMaster Children's Hospital, Hamilton, Ontario. She is now with the Department of Pharmacy, London Health Sciences, London, Ontario.

Jonathan Wong, BScPharm, PharmD, ACPR, RPh, is with the Department of Pharmacy, McMaster Children's Hospital, Hamilton, Ontario.

Mark Duffett, BSc(Pharm), MSc, PhD, ACPR, RPh, is with the Department of Pediatrics, McMaster University, and the Department of Pediatrics, McMaster Children's Hospital, Hamilton, Ontario.

Competing interests: None declared.

Address correspondence to:

Dr Mark Duffett

Department of Pediatrics

McMaster University

1200 Main Street W, Room 1E1A

Hamilton ON L8N $3 Z 5$

e-mail: duffetmc@mcmaster.ca

Funding: None received. 